\title{
P01-003 - Bleeding disorder in FMF
}

\author{
O Karadag ${ }^{1 *}$, T Akin Telli ${ }^{1}$, N Sayinalp ${ }^{2}$, I Ertenli ${ }^{1}$ \\ From 7th Congress of International Society of Systemic Auto-Inflammatory Diseases (ISSAID) \\ Lausanne, Switerland. 22-26 May 2013
}

\section{Introduction}

The most serious complication in Familial Mediterranean fever (FMF) is the development of amyloidosis, which usually determines the prognosis. Amyloid deposition can be systemic or organ-specific. The clinical features of amyloidosis are dependent on the organs involved, type of amyloidosis, rate of amyloid deposition and amount of amyloid fibrils. Organ dysfunction can cause life-threatening bleeding. Amyloid deposition is the main cause of abnormal bleeding but also coagulation factor deficiencies, hyperfibrinolysis, platelet dysfunction and amyloid angiopathy with increased fragility of blood vessels can be regarded as other important pathogenetic factors. Herein a case of FMF amyloidosis with splenomegaly, refractory cytopenia and bleeding disorder is presented.

\section{Case report}

Thirty-one year old male patient was admitted with complaints of upper gastrointestinal (GI) bleeding and hematuria.In his past medical history, he had recurrent attacks of abdominal pain and fever since early childhood and 9 years ago a renal biopsy was performed to evaluate proteinuria and AA amyloidosis was detected. He had been diagnosed as FMF and colchicine treatment was begun. On physical examination, ecimotic skin lesions on lumbar area and legs were found. The abdominal examination revealed painless massive splenomegaly palpable up to the pelvis. Also physical examination revealed markedly thickened skin in each ear in the area of concha and amyloid nodules of ear. Laboratory results were as follows: Hemoglobin level $8.8 \mathrm{~g} / \mathrm{dL}$, white blood cell count:9000/ mm3, platelet count 41000/ mm3, INR level 1.7. Peripheral blood smear examination showed poikilocytosis, acanthocytosis, neutrophils \%61, lymphocytes $\% 38$, platelet count compatible with thrombocytopenia. LDH level was normal and coombs tests were negative. Beta-2 microglobulin level was too high. $(13417 \mathrm{ng} / \mathrm{ml})$. Bone marrow aspiration and biopsy revealed normocellularity of the marrow and deposition of amyloid in the walls of the blood vessels. All coagulation factor levels were decreased in plasma. As the reason of bicytopenia peripheral degradation and splenic sequestration were evaluated primarily. Amyloidosis caused platelet aggregation defect. Because of the high bleeding risk, he underwent radiotherapy instead of splenectomy for hypersplenism. Despite splenic irradiation thrombocytopenia didn't improve, radiation therapy didn't shrink the spleen. Genetic mutation analysis showed homozygous M694V alleles on MEFV gene. Red blood cells, platelets, fresh frozen plasma and fibrinogen were transfused in order to improve bleeding diathesis. On follow-up the nosocomial infections led to exitus through a septic shock.

\section{Discussion}

In Familial Mediterranean fever (FMF), amyloid deposition in any other organ except kidney can also cause morbidity and mortality. Amyloid deposition should be kept in mind in differential diagnosis of FMF patients with refractory cytopenia and bleeding disorder.

\section{Disclosure of interest}

None declared.

\section{Authors' details}

'Division of Rheumatology, Ankara, Turkey. ${ }^{2}$ Division of Haematology, Ankara, Turkey, Hacettepe University Faculty of Medicine, Ankara, Turkey.

Published: 8 November 2013

doi:10.1186/1546-0096-11-S1-A7

Cite this article as: Karadag et al.: P01-003 - Bleeding disorder in FMF. Pediatric Rheumatology 2013 11(Suppl 1):A7.

'Division of Rheumatology, Ankara, Turkey

Full list of author information is available at the end of the article

C 2013 Karadag et al; licensee BioMed Central Ltd. This is an Open Access article distributed under the terms of the Creative Commons 